\title{
Letter to the editor. Re: "Interventional treatment of pain in refractory angina. A review" by Milos Dobias et al. Biomed Pap Med Fac Univ Palacky Olomouc Czech Repub 2014 Jun 19. doi: 10.5507/bp.2014.028. [Epub ahead of print]
}

\author{
Yoav Paz ${ }^{\mathrm{a}}$, Amihay Shinfeld
}

Received: July 16, 2014; Accepted: September 8, 2014; Available online: September 30, 2014

http://dx.doi.org/10.5507/bp.2014.047

\begin{abstract}
${ }^{a}$ General Intensive Care Unit, Tel Aviv Medical Center, Tel Aviv, Israel and the Sackler Faculty of Medicine, Tel Aviv University, Tel Aviv, Israel ${ }^{b}$ Department of Cardiac Surgery, Chaim Sheba Medical Center, Tel Hashomer, Israel and the Sackler Faculty of Medicine, Tel Aviv University, Tel Aviv, Israel

Corresponding author: Yoav Paz, e-mail: pazyoav@bezegint.net
\end{abstract}

\section{Dear Editor:}

We were very interested to read the review "Interventional treatment of pain in refractory angina" by Milos Dobias et al.1. The authors presented an excellent review of antianginal interventional techniques and methods. However, one emerging innovation for the treatment of patients suffering from refractory angina pectoris (RAP) was overlooked, namely that of coronary sinus intervention. We would ask for the opportunity to provide the readers with supplementary information about the Neovasc coronary sinus reducer stent (CSRS) for the treatment of chronic RAP.

In the mid-1990s, we initiated an unusual, novel approach to support the ischemic myocardium. We suggested catheterizing the coronary veins instead of the coronary arteries, and reducing the coronary sinus diameter rather than expanding a narrowed coronary artery. Initially, we studied our novel approach in pig models, when the coronary sinus diameter was reduced to $3 \mathrm{~mm}$ with an hourglass-shaped, balloon-expandable stent, developed especially for this purpose. Eight to 12 weeks after stent implantation, we were surprised to find epicardial and intra-myocardial neovascularization. After a few years of research and development we manufactured the first percutaneous intravenous CSRS and called it "Neovasc", later known as Neovasc Medical, Inc.

The first prospective, open-labeled, safety feasibility human study began in 2004 (ref. $\left.{ }^{2}\right)$. The CSRS was implanted into 15 patients with angina pectoris refractory to medical treatment. All patients underwent uneventful implantations without procedure-related complications and were discharged from hospital 1 to 2 days post procedure. No major adverse cardiac events were reported during a 6-month follow-up period, at which time most of the patients had improved Canadian Cardiovascular Society (CCS) scores compared with baseline (3.07 versus 1.64; $P, 0.0001)$. Improvement was also seen for stress-induced ST-segment depression, as well as for the extent and severity of myocardial ischemia, as shown either by dobutamine echocardiography or by thallium single-photon emission CT.
After 3 years of follow-up no mortality, myocardial infarctions or reducer-related adverse events were evident, and the patients' clinical status continued to improve ${ }^{3}$. Eleven patients underwent computed tomography angiography; all CSRSs were patent and well located in the coronary sinus.

The coronary sinus reducer for treatment of refractory angina (COSIRA) study has already begun and will reassess the efficacy of the CSRS (ref. ${ }^{4}$ ). This trial is a double-blind, randomized, sham-controlled multicenter trial (currently being conducted in Canada, Europe and the UK), for which patient enrollment was completed in May 2013.

On September 27, 2010, the Neovasc CSRS was featured in a "live case" performed in the Antwerp Cardiovascular Institute/ZNA Middelheim in Belgium, and was broadcast to the main arena of the Transcatheter Cardiovascular Therapeutics 2010, the $22^{\text {nd }}$ Annual Scientific Symposium sponsored by the Cardiovascular Research Foundation ${ }^{5}$. The Neovasc CSRS was successfully implanted by the COSIRA trial principal investigator into the coronary sinus of a patient suffering from refractory angina pectoris.

In 2014 Maayan Konigstein et al. reported on 21 successful CSRS implantations in 23 eligible patients, conducted in two medical centers 6 . No device-related adverse effects were observed during the procedures or during the 6-month follow-up period. Canadian Cardiovascular Society (CCS) score diminished from a mean of 3.3 at baseline to 2.0 at 6 months $(\mathrm{n}=20, P<0.01)$, and exercise duration was prolonged from 3:16 to $5: 16 \mathrm{~min}$ ( $\mathrm{min}: \mathrm{sec}$; $\mathrm{n}=8, P=0.05$ ). Thallium SPECT summed stress score and summed difference score were both reduced $(\mathrm{n}=9,21.5 \pm 10$ vs. $13.2 \pm 9, P=0.01$, and $11.1 \pm 6$ vs. $4.7 \pm 4, P=0.007$, respectively). Wall motion score index at peak dobutamine infusion was also significantly improved $(\mathrm{n}=8,1.9 \pm 0.4$ vs. $1.4 \pm 0.4, P=0.046$ ).

In conclusion, CSRS implantation seems to be a safe procedure, providing optional treatment for the improvement of quality-of-life for the many patients suffering from "no-option" RAP. 


\section{ACKNOWLEDGEMENT}

Conflict of interest statement: Dr. Yoav Paz and Dr. Amihay Shinfeld are the inventors of the Neovasc Coronary Sinus Reducer Stent. Currently none of the authors have any commercial or other association with the company whose product is the subject of the review or with a company that manufactures comparable products.

\section{REFERENCES}

1. Dobias M, Michalek P, Neuzil P, Stritesky M, Johnston P. Interventional treatment of pain in refractory angina. A review. Biomed Pap Med Fac Univ Palacky Olomouc Czech Repub 2014 Jun 19. doi: 10.5507/ bp.2014.028. [Epub ahead of print]
2. Banai S, Ben Muvhar S, Parikh KH, Medina A, Sievert H, Seth A et al. Coronary sinus reducer stent for the treatment of chronic refractory angina pectoris: a prospective, open-label, multicenter, safety feasibility first-in-man study. J Am Coll Cardiol 2007;49:1783-9.

3. Banai S, Schwartz M, Sievert H, Seth A, Keren G, Parikh KH. Long-term follow-up to evaluate the safety of the Neovasc reducer: a devicebased therapy for chronic refractory angina. J Am Coll Cardiol 2010; 55:A98.E927.

4. CRT Online - Cardiovascular research technologies. http://www. crtonline. org/pr.aspx?PAGE_ID=7615.

5. Neovasc Reducer(TM) for Refractory Angina, featured in a Live Case Session at the TCT 2010 Conference. Sept 27, 2010. Available from: http://lifesciencesbc.ca/News/Member_Press_Releases/pr09271003. asp Accessed Feb 8, 2011.

6. Konigstein M, Meyten N, Verheye S, Schwartz M, Banai S Transcatheter treatment for refractory angina with the coronary sinus reducer. Eurointervention 2014:9:1158-64. 